\title{
Symbolic Consumption in the Indian Markets: Analysis of Determining Factors
}

\author{
Dr. V. Krishnamohan \\ Professor of Marketing, Dept of Commerce and Management Studies, \\ Andhra University, Visakhapatnam (AP) India-530003 \\ Ms. V. Pragnya Suma \\ Research Scholar (FT), Dept of Commerce and Management Studies, \\ Andhra University, Visakhapatnam (AP) 530003
}

\begin{abstract}
Researchers have tried hard to understand the concept of symbolic consumption and more precisely the reasons for symbolic consumption as it is one of the central issues of concern around which the marketing strategy for many products revolves. There are many products being purchased for the symbolic value they carry, rather than the functional value or the utilitarian value of the product. Researchers classified the needs into functional, emotional and symbolic needs. While the lesser known and understood facts about symbolic consumption and the changing behaviour of consumers are being worked upon by various researches, the constant change in the pattern of this behaviour makes it difficult for researchers to stick to a particular stream and area of research. The term symbolic consumption is used to describe the phenomenon whereby people consume to reflect their sense of self-identity. Symbolic consumption has been addressed primarily not only in consumer studies, but also in anthropology, sociology, economics, marketing, human ecology, and social psychology. Over the period, consumers have constantly changed their perceptions and notions regarding branded products and their value. The driving factors that make the consumer consume or not a particular product are varied and influence the process in various possible combinations of these individual factors. Questions regarding why a product is purchased by a group of people, the recurrence of its purchase or why a product is selected over the others have always been revolving in the minds of marketing groups and researchers. This paper analyses the theoretical aspects of the determinants of the constantly varying consumer behaviour in indulging in symbolic consumption of brands in the Indian scenario with a focus on the determinants which affect the consumer in their buying decision are examined.
\end{abstract}

Key Words: Symbolic Consumption, STP, Marketing mix, Brands

\section{INTRODUCTION}

In the past 40 years, during a period of significant increases in consumed goods across the world, many scholars have addressed the symbolic or meaning-making properties of what people purchase, use, and display. Symbolic consumption has been addressed primarily not only in consumer studies, but also in anthropology, sociology, economics, marketing, human ecology, and social psychology. Over the period, consumers have constantly changed their perceptions and notions regarding branded products and their value. The driving factors that make the consumer consume or not consume a particular product are varied and influence the process in various possible combinations of these individual factors.

Symbolic consumption is the term used when a consumer purchases or uses a product as a result of emotional driving factors as opposed to functional driving factors. The symbolic meaning associated with the product may greatly affect its adoption and use. For example, the 
decision to purchase an item of apparel may not be influenced only, or even primarily, by its color, fabric or design, but the symbolic meaning attached to a given configuration of these tangible features by both the purchasing consumer and by others observing him/her.

The term is used to describe the phenomenon whereby people consume to reflect their sense of self identity. It reminds us of the socially assigned meaning to goods, often tied to desirable attributes for certain identifiable groups in specific contexts. It refers to the meanings conveyed by goods or other consumables, such as apparel, food, living, entertainment, leisure activities, cultural practices, and group membership in a broader social group.

While perceived value is often conceptualized as bi-dimensional, some researchers include a third dimension, suggesting that symbolic benefits such as self-expression or social recognition are additional gratifications, different from hedonic perceptions. There is no real consensus about the classification of symbolic value in previous literature: it has been referred to either as part of the hedonic value or as a specific type of value in itself. For some researchers symbolic meanings and self-expression are classified and explored among hedonic values, while others make a clear differentiation and describe symbolic value as less product-related than hedonic benefits, including self-expression, social approval and self-esteem.

Other studies dealing with the self-concept in consumer behaviour have shown that products can be communication vehicles as far as they refer to images and associations (e.g. Sirgy, 1982). And Belk (1988) has highlighted the ways consumption helps define people's identity in relationship to others. Similarly, the symbolic interactions perspective has described products as social stimuli (Solomon, 1983). Typically, if a consumer, after buying a brand, feels that using this brand provides self gratification, he or she will be more tempted to re-buy it. Findings have shown that self gratification is an antecedent of purchase behaviour and thus brand loyalty (Reed, 2002).

Endless efforts were made by scholars to understand the reasons for product choice and the reasons for consumption. There are many products being purchased for the symbolic value they carry, rather than the functional value or the utilitarian value of the product. Researchers classified the needs into functional, emotional and symbolic needs. While the lesser known and understood facts about symbolic consumption and the changing behaviour of consumers are being worked upon by various researches, the constant change in the pattern of this behaviour makes it difficult for researchers to stick to a particular stream and area of research.

A lot of early work concentrated only on the functional and emotional drivers of consumption. Since there was an insufficiency of the concept as per other researchers, more work was focused on exploring the emotional drivers that lead to symbolic consumption. With increasing number of brands and product lines being available in the Indian market, consumers have created new preferences and reasons for choosing particular products and brands over the others.

Aim:

This paper analyses the theoretical aspects of the determinants of the constantly varying consumer behaviour in indulging in symbolic consumption of brands in the Indian scenario. Questions regarding why a product is purchased by a group of people, the recurrence of its purchase or why a product is selected over the others have always been revolving in the minds of marketing groups and researchers. In this paper, an attempt is made to identify the determinants which affect the consumers in their buying decisions are analysed and explained. 


\section{REVIEW OF LITERATURE}

Researchers have tried hard to understand the concept of symbolic consumption and more precisely the reasons for symbolic consumption as it is one of the central issues of concern around which the marketing strategy for many products revolves. The understanding of consumers perception of consumption is "first gaining some understanding of the meanings that consumers attach to possessions" according to Belk (Belk, 1988: 139). Sometimes products may serve as symbols, and hence may be evaluated, purchased and consumed based upon their symbolic content (Zaltman and Wallendorf 1979, Ch. 8).

The initial models (Cohen, Fishbein and Ahtola, 1972; Zajonc and Hazel, 1982; Burke and Edell, 1989) on consumption revolve around the "economic man" concept, which propose that a cognitive approach is used by the consumer by which he evaluates the value of the various products based on their attributes and then chooses a product that maximizes his utility.

In an article by Park, Jaworski and McInnis (1986), it is stated that "an important factor influencing the selection of a brand concept is consumer needs". Later these models were deliberated and criticized for not having taken into account the emotional drivers underlying the purchase decision. According to Bhat and Reddy (1998: 33) "the rational model is appropriate only for goods which consumers value for their tangible and utilitarian benefits".

Alternative explanations to the drivers of consumption behaviour of customers were later proposed by scholars who worked in this field. The role of emotions was explained in soe of these researches. (Richins, 1997; Bagozzi et al., 1999).

The hedonic aspect of the ct of consumption was explained by (Hirschman and Holbrook, 1982; Babin et al., 1994; Voss, Spangenberg and Grohmann, 2003). The consumption experience and the role it playes in consumer decisions of purchase were the further areas of study. (Mathwick, Malhotra and Rigdon, 2001; Chronis and Hampton, 2002).

While these studies showed a connection between the functional and emotional drivers that lead to consumer decision, a lot of scholars until recently did not pay attention to the symbolic aspects of consumption. (Chitturi, Raghunathan and Mahajan, 2008; Chen, Kalra and Sun, 2009; Levav and McGraw, 2009; Khan and Dhar, 2010). This could be because of lack of proper documented information and empirical derivations that prove symbolic consumption and the fact that consumers have this need to be satisfied was not addressed and considered by many scholars.

An empirical testing tool that compares the symbolic versus the functional value of a brand was first developed by Bhat and Reddy (1998). They demonstrated that a brand can hold these two values simultaneously. A strong correlation between these two values was found by Belen del Rio, Vazquez et Iglesias $(2001 ; 2002)$ who found more differences in the benefits sought at brand level than at the product level. A conceptual framework including functional and symbolic benefits designed for destination branding specifically was proposed by Balakrishnan (2009).

Perceived value PERVAL approach was one of the approaches developed by Sweeney and Soutar (2001) based on which Orth conducted several studies (Orth and Lopetcharat, 2005; Orth, McGarry Wolf and Dodd, 21 2005; Orth and De Marchi, 2007) on the link between brand benefits and purchase intentions. His work displays that the three benefits are significant in predicting purchase intensions of the customers and major differences might also appear due to the product, its characteristics and extent of marketing used in the promotion of the 
product, and also the product experience.

The effects of product attributes (functional, experiential and symbolic) on consumer satisfaction were another important study conducted by Liang and Wang (2004). The effects of the benefits were mostly positive according to their study but sometimes negative in experiential benefits. Symbolic benefits were found to be the most accurate predictor of consumer satisfaction, both significant and positive.

The three benefits were also considered by Blankson and Kalafatis (2007) in their study simultaneously. They state that the positioning strategy of brands should decide the emphasis of benefits. The positioning decides whether the brand aims at giving more functional value or symbolic value to its products or services.

Finally, the interesting model proposed by Tsai (2005b) also verifies that "brand purchase value is dividable into three dimensionalities which in juxtaposition and in interaction exerts direct influences on repurchase intention. Such a discovery provides support to the premise that the traditional economic utilitarian view is not adequate and that socio-cultural symbolism and emotional/affective marketing approaches should also be incorporated into the understanding of purchase value" (Tsai, 2005).

\section{Research Gap:}

From the review of papers related to symbolic consumption, it can be stated that a definitive method of understanding the concept cannot be devised as it is purely dependent on the context and product characteristics of the concerned study and the factors affecting them are constantly changing. These factors differ from country to country based on the past and present situations and the extant of development achieved in the economic and infrastructural positions.

Most of the work done in the area of symbolic consumption as such was done by research scholars in the developed countries. Little information is available on the understanding of the concept among the consumers in India. With the impact of globalized culture and crosscultural concepts in both the work place and also personal lifestyles, an understanding of the unknown utilization of the concept can be brought to light and can provide substantial information in devising new marketing and branding strategies for major players in the market.

\section{Research Questions that are addressed in this paper:}

- What are the major role playing factors in consumer buying decision?

- How can brands understand its consumer preferences?

- How can these factors help in strategising STP of a brand?

- Impact of symbolic consumption on the marketing mix

\section{Major Role Playing Factors:}

While the factors that determine the symbolic consumption of a product are numerous, the major and largely affecting factors can be significantly classified into three major factors in the Indian scenario.

- Cultural aspects

- Societal status

- Timing / Seasonality

- Personal attributes 
- Need theory

- Cost

- Brand culture

Culture is considered an external factor in influencing consumer behavior. Since different cultures have different values, they will have different buying habits. Marketing strategies should reflect the culture that is being targeted. The strategy should show the product or service as reinforcing the beliefs, values and customs of the targeted culture. Failing to do so can result in lost sales and opportunities.

It plays a very important role in the purchase decision of the consumer. The theory works more so better here considering the cultural richness in India. With varying cultures, traditions and values just within the country, brands need to take a weighted decision on the strategies for better marketing and sales.

Apparel, food and lifestyle products, which are the most sought after commodities, have various styles in various parts of the country. With increase in the global approach of all the companies and brands, there is a symbolic buying behaviour amongst the young working class of this country which is within the age group of 23-35years.

Culturally, for example, Saree is the most used apparel in India. The young generation however opt western wear both for their work and personal life. Therefore for brands, the demographic target is to be decided strategically.



Source : Cengage learning.

Societal Status is a factor that can be segmented but is a prominent factor affecting individually in each segment. If the population can be categorised based on the spending capacity of the consumers, symbolic consumption is observed at every layer of these categories.

Social class can have a profound effect on consumer spending habits. Perhaps the most obvious effect is the level of disposable income of each social class. Generally, the rich have the ability to purchase more consumer goods than those with less income, and those goods are of higher quality. There is also a distinction in the type of goods purchased. For example, the upper class 
tend to be the primary buyers of fine jewellery and often shop at exclusive retailers. The lower class, in contrast, are much more concerned with simply getting by; they focus more on necessities.

While the rich and affluent people have a set of commodities that they consider as representative objects of their status, so do the other sections. The cost of these commodities might vary but purchasing a product for its symbolic value and not functional value is always present in each segment.

Awareness amongst marketers regarding social class of their target market is most essential. If a marketer wishes to target efforts toward the upper classes, then the market offering must be designed to meet their expectations in terms of quality, service, and atmosphere. A clear understanding of the dynamics of the social class is necessary.

Timing/Seasonality in the Indian context plays a pivotal role in determining the seasonal needs of consumers based on the special occasions that are celebrated or observed. While this can be considered as an off shoot of the cultural aspect, some might also differ in terms of selective requirements of customers where the needs and requirements are suddenly found at an increased level than normal.

An example of this would be a wedding in the family or a personal event where the buying capacity of the customer is raised acutely in a short period of time. This applies specifically in the Indian scenario as the magnitude of materialistic utilization of goods during such occasions is far higher than the same in other countries.

Personal Attributes can be considered as the unique factor where the difference is felt and seen at an individual level. In a given economic segment, there could be an individual with higher buying habit in comparison with the rest of the clan. In such a case, the individualistic traits of the person alone determine the symbolic buying nature of the product and not the other factors.

While these individuals form a major source of the symbolic buying behaviour process in a society, they are unaffected by their basic needs but are mostly under the influence of personal buying satisfaction and delight. They also form the base of the symbolic consumption cycle where one person becomes the user who communicates a particular trend in the society as a symbol of their status which soon becomes a product of symbolic importance more than its utilitarian needs.

Consumer self image is one major concept that has a greater impact on the perception of symbolic value of products. To understand the types of consumer self-image, the chart below classifies them. 


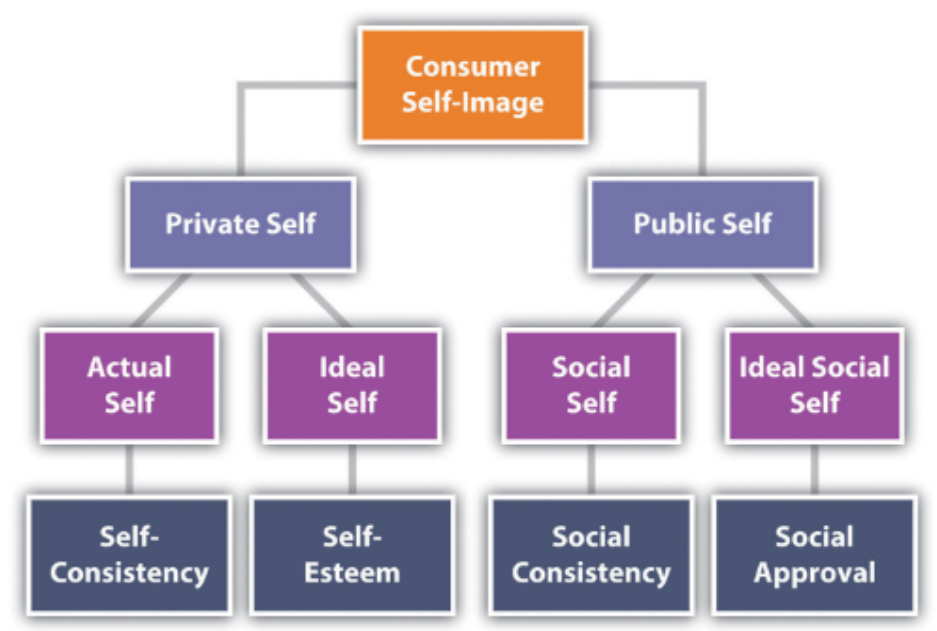

Source : Internet

Need theory as proposed by David McClelland soon after Maslow's "Hierarchy of needs", is another determinant where the psychological need of the customer is alone a major part of the consumers mind set. Of the three types of needs, the need for affiliation is the one that plays a major part. It makes an individual want to be socially accepted and affiliated to a group.
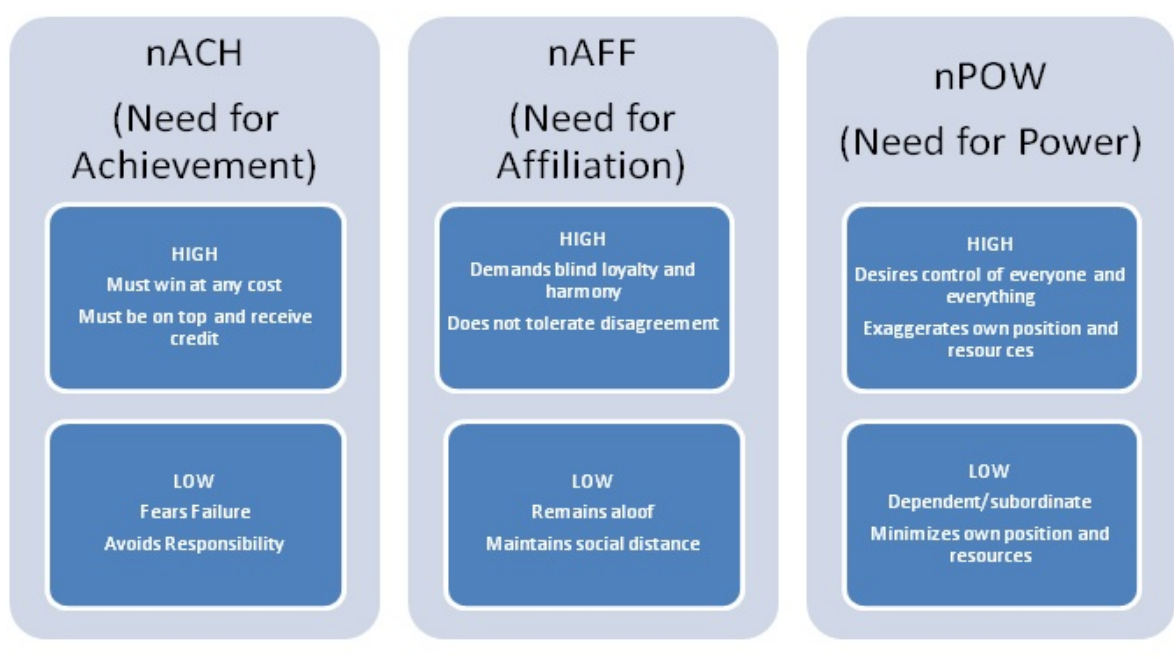

This also includes higher interaction amongst the group to get a sense or feeling of acceptance in the group. This might sometimes require the individual to use products or services which makes them feel like a part of that group. This is the most symbolically consumed method where only the symbolic value of the product is considered.

Cost is one interesting feature which is observed to be both directly and inversely proportional to the symbolic buying behaviour based on the segment of the economic group we are taking into consideration.

In certain cases, a lower cost for a product with equal qualities as any other costlier product in the same group, is taken as an advantage and it becomes a product of interest. Here, though the cost is less the product becomes accepted for its utilitarian and functional properties along with the required look which makes it a symbolically accepted product in that group. This generally happens with the upper middle section of the society. Here cost is inversely proportional to their product buying behaviour. 
In the higher sections of the society, cost is considered as a directly proportional entity of status and quality. Though a product of equal quality is available at a lower cost, it is considered below their status and a costlier product is considered as a symbol of their status. A simple wallet can be an example here. A good wallet with a normal cost might be considered below level in comparison with a costly wallet available in a huge branded outlet even though their quality is same if not the former being superior to the later.

Brand culture can be considered as the most prominent driver of symbolic consumption. In India, brand consumption is by nature considered as a status symbol and a superior buying behaviour. In the last two decades after the advent of globalization and introduction of many national and multinational brands in the market, this pattern and notion in the customers has considerably increased and has now reached a level where brands are again segmented as normal and premium.

Brand cultures can be read as 'branding' cultures in that their cultures of production mark or brand their producers and consumers, for better or for worse. And, they are also branding cultures in so far as they seek to brand the everyday, to put their mark on how we eat (McDonald's), sleep (Sleepwell ), drink (Coca-Cola), defecate (Pampers), talk (Vodafone, airtel), walk (Paragon), or simply enjoy a moment of relaxation (Kit-Kat)

In all sections of the society and in all demographics, consumers prefer branded products to non-branded ones. Brands with lower pricing and good quality are the more preferred brands as consumers consider them as symbols of their buying capacity and satisfies their self esteem.

\section{ROLE IN SEGMENTING, TARGETING AND POSITIONING:}

Segmenting, targeting and Positioning (STP) is a three step process where firms first determine the kind of customers that exist. The second step involves selecting the group which are best off trying to serve or reach and the third step involves implementing the segmentation by optimizing the product for the specified group of customers.

Segmentation involves finding out the different kinds of customers with different needs existing in the market. Based on the strategy chosen by the marketing firms, viz differentiated, undifferentiated and concentrated, the choice of a target segment is made. Considering the concept of symbolic consumption in segmentation calls for some tough choices. The variables that can be used in differentiating consumers are huge in any given product category and in practice, it becomes highly difficult to work with more than a few of them at once. Thus, the variables which will be most useful in distinguishing different groups of consumers need to be determined. Symbolic consumption and related research generally requires segmentation based on lifestyles and values. 


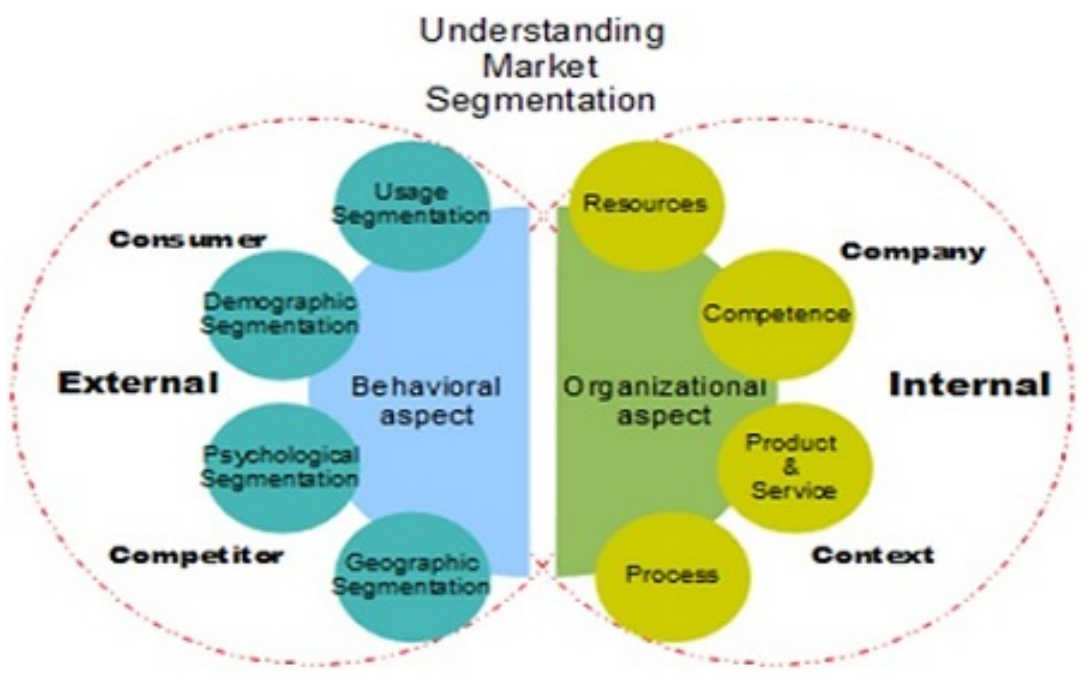

The next step, Targeting, is where one or more of the chosen segments are targeted to be served or reached. When we try to give the customer a value beyond the functional use of a product we need to target the customer in a way that the information is reached. This process should firstly be, knowing the target segment and an understanding of how competitors currently serve the group. Secondly, being able to estimate the size of the segment and methods to widen and broaden it. Thirdly, an introspection of the strengths of the marketers as a firm, which aids in analysing their ability to properly reach the target market by creating a value for themselves and to the customer.

Positioning involves implementing our targeting. For example, Apple Computer has chosen to position itself as a maker of user-friendly computers. Thus, Apple has done a lot through its advertising to promote itself, through its unintimidating icons, as a computer for "nongeeks." The Visual C software programming language, in contrast, is aimed a "techies."

Repositioning involves an attempt to change consumer perceptions of a brand, usually because the existing position that the brand holds has become less attractive. Repositioning in practice is very difficult to accomplish. A great deal of money is often needed for advertising and other promotional efforts, and in many cases, the repositioning fails.

Effective repositioning involves an understanding of the perception of one's brand and the competitors brand by the customer. Multidimensional scaling is one approach to identifying consumer product perceptions. Here, we identify how products are perceived on two or more "dimensions," allowing marketers to plot brands against each other. It may then be possible to attempt to "move" one's brand in a more desirable direction by selectively promoting certain points.

There are two main approaches to multi-dimensional scaling. In the a priori approach, market researchers identify dimensions of interest and then ask consumers about their perceptions on each dimension for each brand. This is useful when (1) the market researcher knows which dimensions are of interest and (2) the customer's perception on each dimension is relatively clear (as opposed to being "made up" on the spot to be able to give the researcher a desired answer). In the similarity rating approach, respondents are not asked about their perceptions of brands on any specific dimensions. Instead, subjects are asked to rate the extent of similarity of different pairs of products

IMPACT OF SYMBOLIC CONSUMPTION ON THE MARKETING MIX :

The 7 P's of marketing mix are Product, Promotion, Price, Place, People, Process and Physical 
evidence. Each of this is in one way or the other contributes to a product being consumed by the consumer.

While considering the impact of symbolic consumption in each of these components, it needs to be kept in mind how each of the components can be modified to create value in the customer's minds. When we consider products, they are to be designed to create value to the customer which the consumer believes gives him a sense of belonging to a higher societal group. This comes not just by creating the product but also the associated factors like the brand positioning, advertising etc which makes the customer believe that the ownership of that product adds value in his mind.

The quality and the convenience of use needs to be considered as a priority to make the consumers develop an affinity towards the product so that it can sustain in today's highly competitive market. In the process, the product experience which the consumer gets should be improvised so that the consumer returns for the same product again. Customer retention is the key in maintaining the numbers in the targeted segments. Customer delight is the new term used in marketing where utmost priority is given to making the customer feel good about the product.

Customer oriented promotion and reach should be achieved by the marketers so that a symbolic value is created to the product. The promotion process should also see to it that the product is known among all the people or societal groups. Demographic targets should be reached based on their specific needs so that people are satisfied with the product and also its price. A design based on the extent to which the marketer intends to create a symbolic value to the product needs to be created.

The process of reaching the customers should not be persuading and imposing that the customers lose interest in the product. As it is said, it's all in the looks. The physical appearance of the product is what attracts the customer to the product. So, the packaging and appearance essentially need to be user friendly and attractive to make the consumers want to buy the product. A product of similar lines on the shelves should not catch the attention when trying to reach out for ours. Attention to all the components in the marketing mix adds a dimension of value creation at every step which in turn reflects in the consumer buying decision based on the symbolic value which marketers look for.

\section{SUMMARY AND CONCLUSIONS}

In today's market, symbolic consumption is the unheard but the strongest underlying driving force of consumer buying behaviour. It determines the success of a product and its future utilization and acceptance. Marketers and companies need to concentrate on the very generic nature of the consumer buying behaviour and the effect symbolic consumption is having on it in order to succeed in the market place.

The determinants examined in this paper give a bird's eye view of the major role playing factors. The effect and impact these have on the STP and marketing mix have also been detailed. These are individually concepts which can be further researched upon to design the right marketing strategy for a product.

The determinants also help us in understanding the consumer perception of products, prices or the product experience which in turn determines the recurrence of the product buying behaviour of the customer. 
The success of a brand depends primarily upon its ability to keep up with the changes in buying behaviour trends at every step. Small but significant changes right from the grass root level lead to major results leading to the success and longevity of brands in the market place.

In conclusion we have to stress the fact that symbolic consumption is the factor which has an impact on consumer purchase decision-making process. Brands provide information about products and create associations that affect the mind of the consumer in purchase process. In todays marketing, a very important category of consumer behavior research is symbolic consumption. Suitable forms of marketing activities as a whole can create a positive effects on consumers making the marketers efforts more successful.

\section{References:}

Babin, B. J., Darden, W. R. and Griffin, M. (1994). Work and/or Fun: Measuring Hedonic and Utilitarian Shopping Value. Journal of Consumer Research, 20, 644-656.

Balakrishnan, M. S. (2009). Strategic branding of destinations: a framework. European Journal of Marketing, 43(5/6), 611-629.

Belen del Rio, A., Vazquez, R. and Iglesias, V. (2001). The role of the brand name in obtaining differential advantages. Journal of Product and Brand Management, 10(7), 452- 465.

Belk, R. W. (1988). Possession and the Extended Self. Journal of Consumer Research, 15(September), 139-168.

Bhat, S. and Reddy, S. K. (1998). Symbolic and functional positioning of brands. Journal of Consumer Marketing, 15(1), 32-43.

Blankson, C. and Kalafatis, S. P. (2007). Congruence between Positioning and Brand Advertising. Journal of Advertising Research, 47(1), 79-94.

Burke, M. C. and Edell, J. A. (1989). The impact of feelings on ad-based affect and cognition. Journal of Marketing Research, 27, 69-83.

Chen, T., Kalra, A. and Sun, B. (2009). Why Do Consumers Buy Extended Service Contracts? Journal of Consumer Research, 36, 611-623.

Chitturi, R., Raghunathan, R. and Mahajan, V. (2008). Delight by Design: The Role of Hedonic Versus Utilitarian Benefits. Journal of Marketing, 72, 48-63.

Chon, K. S. (1992). Self-image/destination image congruity. Annals of Tourism Research, 19(2), 360-363.

Chronis, A. and Hampton, R. (2002). Theory building for experiential consumption: The use of the phenomenological tradition to analyze international tourism. American Marketing Association. Conference Proceedings.

Hirschman, E. C. and Holbrook, M. B. (1982). Hedonic Consumption: Emerging Concepts, Methods and Propositions. Journal of Marketing, 46(Summer), 92-101.

Khan, U. and Dhar, R. (2010). Price-Framing Effects on the Purchase of Hedonic and Utilitarian Bundles. Joumal of Marketing Research, 47, 1090 -1099.

Levav, J. and McGraw, P. (2009). Emotional Accounting: How Feelings About Money Influence Consumer Choice. Joumal of Marketing Research, 46, 66-80.

Liang, C.-J. and Wang, W.-H. (2004). Attributes, benefits, customer satisfaction and behavioral loyalty - an integrative research of financial services industry in Taiwan Journal of Services Research, 4(1), 54-91.

Mathwick, C., Malhotra, N. and Rigdon, E. (2001). Experiential value: conceptualization, measurement and application in the catalog and Internet shopping environment. Journal of Retailing, 77, 39-56.

Orth, U. R., McGarry Wolf, M., et al. (2005). Dimensions of wine region equity and their impact on consumer preferences. Journal of Product and Brand Management, 14(2), 88-97.

Park, C. W., Jaworski, B. J., et al. (1986). Strategic Brand Concept-Image Management. Journal of Marketing, 50(October), 135-145.

Richins, M. L. (1997). Measuring Emotions in the Consumption Experience. Journal of Consumer Research, 24(2), 127-146.

Sweeney, J. and Soutar, G. (2001). Consumer perceived value: The development of a multiple item scale. Journal of Copyright $\odot$ Society for Science and Education, United Kingdom 
Retailing, 77(2), 203-220.

Tsai, S.-p. (2005a). Impact of personal orientation on luxury-brand purchase value. International Journal of Market Research, 47(4), 429-454. Tsai, S.-p. (2005b). Utility, cultural symbolism and emotion: A comprehensive model of brand purchase value. International Journal of Research in Marketing, 22, 227- 291.

Voss, K. E., Spangenberg, E. R. and Grohmann, B. (2003). Measuring the Hedonic and Utilitarian Dimensions of Consumer Attitude. Journal of Marketing Research, 40(3), 310- 320.

Zajonc, R. and Hazel, M. (1982). Affective and cognitive factors in preferences. Journal of Consumer Research, 9 , 123-131. 